\title{
Give Us Space! \\ Augmented public space geographies in the changing public/private relationships
}

\author{
Manfredo Manfredini (Lead Author) \\ University of Auckland \\ m.manfredini@auckland.ac.nz \\ Adrian Lo \\ University of Auckland \\ adrianlo20II@gmail.com \\ Dory E. Reeves \\ University of Auckland \\ d.reeves@auckland.ac.nz
}

\section{The inception of meta-public space}

The aim of this article is to reflect on and share the findings of the Networking Event 'Give us Space: Augmented public space geographies in the changing public/private relationships.' The Event addressed emerging spatial issues in the production of the public realm of contemporary cities. This topic has been at the centre of the discourse on urbanism in both humanities and social sciences for decades, reflecting the increasing interest in spatial problems that have contributed to the crisis of public life in the socioeconomic, cultural and political spheres. The recent pervasion of spatial privatisation and public sphere mediatisation processes require a refoundation of this discourse. The discussions addressed some of the key areas of concern raised by the New Urban Agenda (NUA) related to open space, focusing on socio-spatial problems in the pervading production of semi-public spaces in contexts of rapid urbanization. Using a comparative urbanism perspective that highlighted the expanding role of digital geography, it elaborated upon specific Sustainable Development Goals of the UN 2030 Agenda for Sustainable Development. These are the goals concerned with good health and well-being (3), reduced inequalities (I0), sustainable cities and communities (II), and partnerships for the goals (I7).

The event created a platform for knowledge exchange and networking amongst stakeholders. This aimed to I) build capacity in both research and practice; 2) identify problems, limitations, and opportunities with respect to the various actors and stakeholders of urban public space; 3 ) highlight issues concerning less advantaged groups in society: children, youth and elderly, 'differently-able,' indigenous people, marginalized genders, migrants and socioeconomically deprived people.

Primary consideration was given to NUA-related research advocating the 'right to the city' in the transformation of urban public space. Reference to issues of disappearance of the commons (Harvey, 2012: 67-87), renouncement to the 'open city vision' (Sennett, 
2018), and colonisation of the digital infosphere' (Fuchs, 2014), framed the critique of spatial control and over-determination exercised by hegemonic powers in the production of public space. This particularly concerned progressive processes of civil exclusion, dispossession, segregation, and abstraction that adopt displacement and spectacle to sedate mounting fear of the 'stranger' and disguise the perception of severe inequality. Design disciplines such as architecture, urbanism and planning, have increasingly struggled in engaging with these profound on-going transformations. Their difficulties are exacerbated by the deep changes in the space caused by the rapidly expanding role of the digital public sphere. The city and its core spatialities of relational life can no longer be addressed without redefining the approach to the new digitally augmented public realm. Understanding the emerging conceived, perceived and lived conditions of publicness is crucial to support the social, cultural, and psychophysical well-being of the inhabitants of cities of the digital age. Urbanists, designers, and place-makers need to rethink the theoretical framework as well as the conventional processes, methods and practices for analysis, project, and delivery of visions, strategies, and tactics.

The 'Give us Space' event was designed to propose a refoundational discourse of public spaces that, instead of tending to erase the legal, cultural, and performative tensions that exist between public and private domains in public space, comes to terms with the ambivalent and conflictual nature of contemporary publicness. This approach acknowledges the impossibility of considering the institutive historical metaconceptual spatial framework of the public/private dualism, but recognises the inescapable and impermanent ambiguity of the exclusive separation between collective and personal realms. The analysis of factual ambivalences found in the key public spaces of our cities complements the investigation of the widely studied phenomenon of public sphere pervasion in the private realm (Mitchell, 2003: 28-29). It shows the ambivalence of incessantly appearing private instances in public or parochial realms through more-thanvirtual embodiments of the digital infosphere: the formation of a new kind of space, the 'meta-public space.' The epitome of this new spatiality is found in semi-public places at the core of consumption places, as evolution of pseudo-public spaces of hedonic consumption. This space includes the realms of spectacular deception of civicness with territorial stability, such as 'malled' urban centres and privately owned public spaces. The comparative urbanism method adopted at the Event enabled to systematically study similarities and differences among urban processes regarding the meta-public space. The session was started with a critical introduction of key characteristics of the new space as found in urban centres of rapidly developing cities in Asia and Australasia, highlighting the disjoined and introverted, yet hyper-connected and digitally augmented, spatialities (Manfredini, Jenner \& Xin, 20I7). The elaboration revolved around two key phenomena: I) enhanced prosumption as collaborative and participatory consumption, and 2) augmented transduction as coded de-territorialising and re-territorialising spectacle (Manfredini, 2017). These phenomena are empowered by the pervasion of virtual, augmented, and mixed-reality applications that have scaled-up the spatial complexity and differential process, prompting a strong recombination of the rules of engagement of people with their own civic realm. This radical transformation of the relational practices can, if not subsumed by sectarian polarizations, pave the way to a repoliticisation of semipublic spaces.

Central places, like the more-than-consumerist megamalls, conceived and produced by hegemonic powers according to the civic-adverse, formal and quantitative imperatives of globalisation need to be remapped in order to counter the process of minimising 
distinction and repressing relationality that, as Henri Lefebvre posited, by "falling prey of abstraction" alienates the civic (1991: 49). Advocating for an effective and efficacious implementation of the NUA in the meta-consumerist age, therefore includes urging eminent place-makers, such as designers and urban planners, to acknowledge their new role and take full responsibility in the development of augmented prosumeristtransductive spatialities towards a more pluralistic, participative and democratic city. This tenet was elaborated in the working groups of the Event as reported in the following paragraphs.

\section{Public spaces for social integration and inclusion}

Social and economic exclusion and spatial segregation are often an irrefutable reality in cities: public spaces clearly demonstrate how people can be socially excluded or discriminated in cities, whether they are children, elderly, women, differently-abled, or from a foreign country. The NUA has a vision of 'cities for all,' where cities are for equal use and enjoyment, promoting inclusive, safe, healthy, and affordable cities for all inhabitants without any kind of discrimination (NUA, 2016: II). It promotes civic engagement from all inhabitants, engendering a sense of belonging and ownership, prioritizing "safe, inclusive, accessible, green and quality public spaces that are friendly for families, enhance social and intergenerational interactions, cultural expressions and political participation." (I3b)

Children and youth semi-public space issues: The NUA promotes access to quality basic services and public spaces for all, to enhance safe, diverse, and social intergenerational interaction. It takes into consideration children and youth in the promotion of "safe, healthy, inclusive and secure environment in cities and human settlements enabling all to live, work and participate in urban life without fear of violence and intimidation" (NUA, 2016: 39). Studies about growing up in cities, particularly in Australia, described children growing up in rapidly urbanized centres living in overcrowded, unsafe, and polluted environments, with little opportunity for recreation and play (Malone, 200I: 6). The discussions in the networking session, concluded that spaces should have plenty of leisure and natural green spaces to facilitate child health and well-being in urban environments (NUA, 2016: 14c). Facilities should be provided which encourage and allow children to identify and connect with their physical, social, and natural environment (Malone, 1999: 21). One particular case study which arose from the discussion was from Jakarta, Indonesia. In 20I5, the Jakarta Capital City Government established a policy to revitalize a number of parks into interactive community parks called RPTRA (Child Friendly Integrated Public Space). These revitalized parks (funded by a private company through a government and private sector partnership), are multi-purpose child-friendly community spaces, and typically consist of a playground, a field, hall, a library with WIFI, and a garden for fruit and vegetables.

Migrants and grassroots semi-public space issues: The NUA recognizes and respects the full human rights of refugees and migrants, regardless of migration status, and promotes inclusive prosperity supporting both formal and informal economies. Though the movement of large populations into cities poses various challenges, the NUA acknowledges that migrants (as well as the working poor in the informal economy, particularly women, including unpaid and domestic workers) can also bring about significant social, economic and cultural contributions to the urban environment and life 
(NUA, 2016: 28 and 59). The discussions highlighted that migrants-local people can constitute forms of socio-spatial networks with very complex patterns of territorializations that show unique examples of inclusionary agonistic and more-thanrelational urban public space, where all have unrestricted right to participate in the production of the city. However, migrants and local people often must improvise in their use of public spaces and engage in critical non-compliant informal activities. Security in public spaces is an issue, and one case study was provided regarding the unique sidewalk encroachment in the Ancient Quarter of Hanoi, Vietnam (Manfredini \& Ta, 2017). Here, the intertwining and dynamics of formal and informal territorialisation of public spaces strongly contributes to the creation of successful streets that support the social, cultural and economic well-being of citizens.

Acknowledging the NUA, an important point made in the forum was the celebration of differences and what these migrants can bring in terms of socially and culturally diverse contributions to urban life. However, although migrants and grassroots could bring new life into urban areas, their presence in public space and the areas they congregate could be contested (Manfredini \& Ta, 2016). To illustrate this, Filipina migrants' appropriation of public spaces in Hong Kong clearly demonstrates how public spaces are not only a platform for diversity within the city, but also a platform where various interested actors or parties can engage or even contest in its use with social, cultural, economic, or even political agendas (Low, 2002).

Gender, 'differently-able,' and indigenous semi-public space issues: The NUA recognizes that various forms of marginalization and discrimination need to be addressed, particularly in relation to women and girls, children and youth, elderly, persons with disabilities, indigenous peoples and local communities, as well as refugees and migrants (NUA, 2016: 20). Paragraph I $3 \mathrm{c}$ of the NUA raises the issue of gender equality and the empowerment of all women and girls by ensuring their effective participation and equal rights, whilst preventing and eliminating discrimination and violence in private and public spaces (NUA, 2016: 13c). Recent literature on this topic describes an apparent lack of recognition and attention to the needs of women within the right to the city, grounded in their everyday experiences, whether they are workers, carers, or simply enjoying leisure activities (Reeves, Parfitt \& Archer, 2012; Reeves \& Zombori, 2016). Women face immense challenges as their rights become restricted in their search for place and feelings of belonging in today's cities. This is particularly evident in feminist geographical studies of London and Jerusalem discussed by Yasminah Beebeejaun (2017). Here, she states a case for women challenging the norms of public space through street protests. However this is just a temporary means of asserting women's right to be in public spaces and their need for more permanent recognition. By reengaging within the multiple uses of urban spaces, developing frameworks which draw more upon women's everyday experiences and spatial uses, which are attentive to their differences, can provide a more fine-grained understanding of the issues and the potential to support a fuller sense of gendered rights to everyday life in urban environments (Beebeejaun, 2017: 33I). Space is not just a physical container of life, but it is socially produced, dynamic, ambiguous, and contested (Rob Kitchin, 1998, 343-45). In today's urban environments, people recognized as differently-abled are still marginalized and excluded as a result of a disabling environment. Spaces have become socially produced to exclude differently-abled or disabled people and have been organized to keep these people "in their place' as well as textualised to convey to such people that they are "out of place" (Steinfeld, Maisel \& Levine, 20I2). A number of 
concerns, raised in the thematic session at the Event, revolved around the duty of care to provide public spaces for people previously made invisible through insensitive urban planning and design.

In the context of current urban planning practices and in existing public spaces, disabled people are 'locked out,' separated, and marginalized to the peripheries. Policies prioritize the perception and values of 'able-bodied' persons, and thus aim to normalize disabled people, rather than accommodating disabled people for who they are (Steinfeld, Maisel \& Levine, 2012: 347). Rather than denying differently-abled or disabled people access to important decision-making within today's cities, all people should have the right to participate in the making of the city. Indigenous peoples have sovereign authority over their land which needs to be recognised through participatory processes and partnership models for indigenous governance. There needs to be regard for indigenous values and knowledge, sites of significance, traditional names, and regeneration of natural resources and systems, as well as work with indigenous artists and designers through the spatial design process for distinct outcomes (Auckland Council, 2017).

Age-friendly semi-public space issues: The NUA seeks to address the social, economic, and spatial implications of ageing populations as well as promote age- and gender-responsive planning (NUA, 2016: I3f and 62). In the discussions at the Event an 'age friendly city' was discussed in the context of 'a city for all ages.' We can lose key elements of our identity when we age and may potentially lose particular social and cultural connections. This has been noted as one of the least spatially regarded aspect in studies on marginalisation within urban environments (Buffel \& Phillipson, 2016: 95). Buffel and Phillipson describes the challenge to create urban environments which support the equal rights of older people with others to a 'share' of urban space which is both safe and inclusive (Buffel \& Phillipson, 2016: 97-98). Lefebvre's concept of 'the right to the city' and Harvey's 'right to make our cities and ourselves' need to be linked to the debate about developing agefriendly cities, such that people of all ages can enjoy full 'urban citizenship' and make full use of urban public spaces. This right simultaneously means guaranteeing older people a voice, ability to appropriate and associate urban space, participate in processes decisionmaking processes regarding the production of such spaces (Buffel, Phillipson \& Scharf, 2012: 607-609). We should guarantee access to everyone to live and participate in the production of the city, instead of providing solutions for predetermined categories of users with generic sets of disabilities. To implement the NUA's vision of cities for all, there is a general goal to involve and engage everyone: it is a civic responsibility to establish efficacious, design-led participative decision-making and planning processes. Public spaces for cultural consumption, tourism, and spectacle: The NUA acknowledges the importance of culture and diversity as sources of enrichment for people and the sustainable development of cities, and recognizes that culture needs to be considered in the promotion and implementation of new sustainable consumption and production patterns in cities (NUA, 2016: 10). Regarding public spaces of consumption, of particular interest today is how public spaces are reinstated into pluralistic forms of socio-spatial relationality that transforms the collective realm from semi-public or public into a 'metapublic' state in place-based augmentation of the culture of consumption emerging in public spaces with enhanced atmospheres of either produced or induced authenticity (Manfredini \& Jenner, 2015).

Paragraph 19 of the NUA acknowledges the issues facing the least developed countries, particularly those which can be affected by natural disasters, like Nepal, stating that attention should be given to address their unique urban development challenges. The 
Kathmandu Valley is a major tourist destination and consists of seven UNESCO World Heritage Sites, and a particular set of urban public spaces rich in historic traditions, such as the squares of markets and royal palaces. In the commodification of public space and culture for tourists, culture is staged and authenticity is challenged, as local people engage with cultural consumption and translocality of space to support the growing tourism industry (Morimoto, 2015). In the main touristic centres of the capital city, Kathmandu (Basantapur), Patan and Bhaktapur, foreign tourists come to consume 'Nepalness,' whereas locals come to consume global cultures. Urban spaces are transformed, decontextualised and distorted into venues for exotic spectacles. As Robert Shepherd claims, "what was once pure and authentic has become spoiled and commodified" (2002: 183). However, what makes some aspects of the Kathmandu model relevant to the "urban development challenge' is the socialisation form that this resilient community has developed since the major natural disasters (20I5 Nepal earthquake). Here, the disruptive effects of tourism on sustainable development have been mitigated by a distinctive phenomenon of local community empowerment that has improved livelihood and expanded participation in the exercise of citizenship.

\section{Give us Space! at the $9^{\text {th }}$ World Urban Forum}

The "Give Us Space!" networking session at the WUF9 was held and organized by the University of Auckland in relationship with other partner universities and organizations. This Event fostered a discussion on public space as a common good, by means of sharing and critically evaluating emerging problems in the public realm in different geographical contexts with regards to spatial conception, representation, and everyday life experiences. Focusing on socio-spatial relationality it rethought and raised awareness of its importance to contribute to a successful implementation of the New Urban Agenda, promoting well-being in cities and creating safe, inclusive, accessible, public spaces for all. Specifically, it addressed a crucial kind of public realm: the semi-private space. This space, which often presents the highest levels of relational urban life, is characterized by complex mechanisms of production and control that, while strongly enhancing safety and comfort, pose severe limits to the exercise of the 'right to the city.'

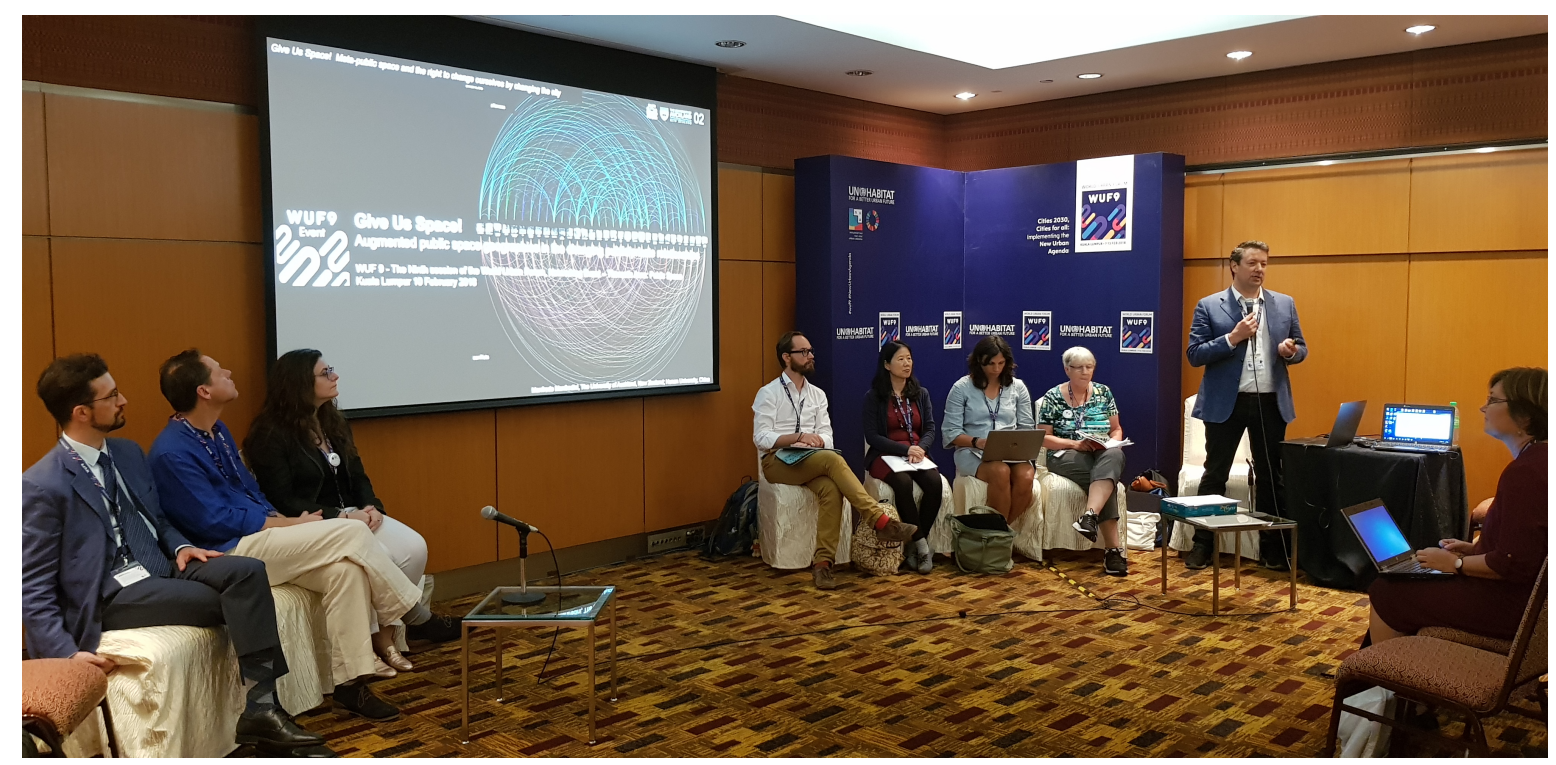

Fig. I Give us Space! session at the $9^{\text {th }}$ World Urban Forum.

I76 | The Journal of Public Space, 3(I), 20I8 | ISSN 2206-9658

City Space Architecture / Queensland University of Technology / UN-Habitat 

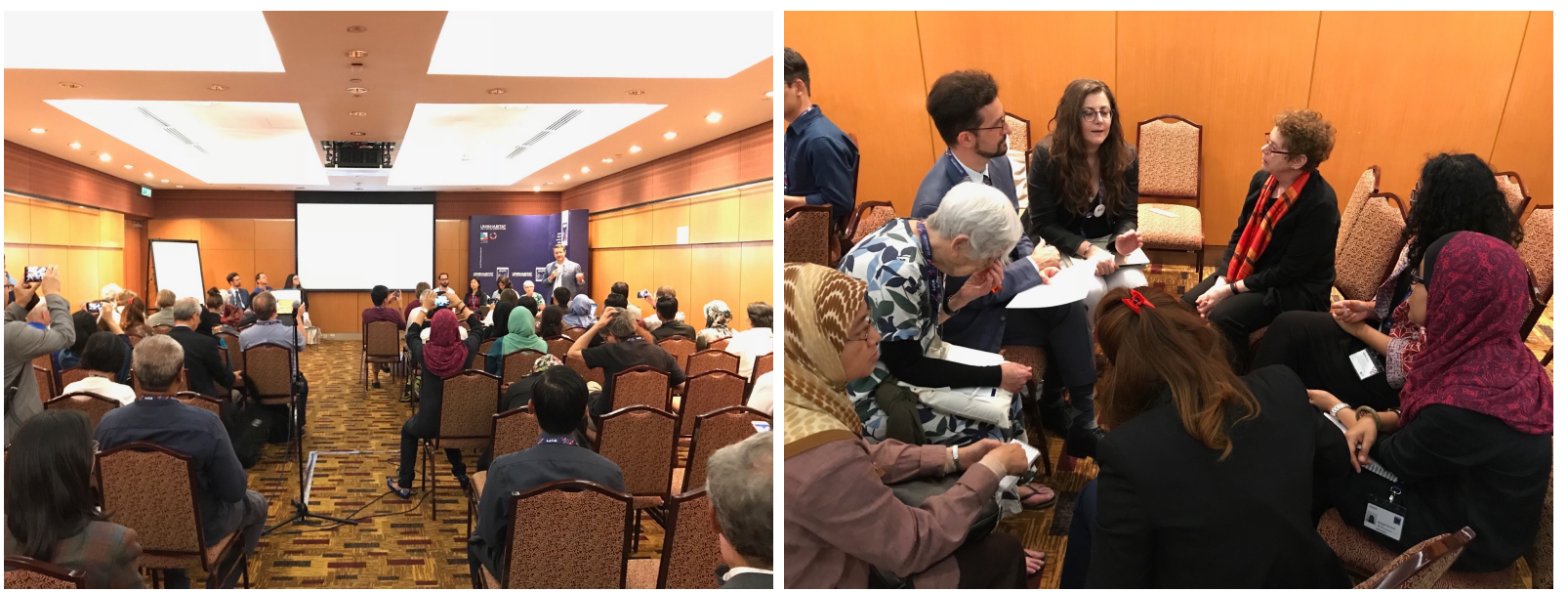

Fig. 2 and 3. Give us Space! session at the $9^{\text {th }}$ World Urban Forum.

The audience was asked to contribute to the issue of privatisation of public space by providing insights and reflections in small groups. A collective question was posited: what is the most relevant emerging critical problem in private use of public space and what are the ways of addressing these issues? Each group had to summarize relevant outcomes from their discussions which were then shared at the end of the session.

\section{Conclusion}

In the wake of the increasing blur of public and private realms in today's cities, brought about by technological advancements and the inherent contradictions of hyperconsumerism, augmented spatialities mediated through communication-based digital spheres provide the main access to the public sphere in public spaces, constituting a form of re-politicisation and empowerment of the individual in the open, permeable, and recombinant 'meta-public space'. The various socio-spatial problems in the production of these semi-public spaces were critically addressed in productive sessions that found a common need for further research. Recommendations were made to pay particular attention to the opportunities and limitations of the global spread of the new complex blurred spatiality whilst simultaneously recognizing the differences of the diverse locale and range of actors and their issues in urban public spaces. This can guarantee the exercise of the right to the city and citizenship in a democratic, participative, and pluralist production of the urban space.

\section{References}

Auckland Council (2017). The Auckland design Manual, Maori Design. Retrieved at: www.aucklanddesignmanual.co.nz/design-thinking/maori-design.

Beebeejaun, Y. (20I7). Gender, urban space, and the right to everyday life, Journal of Urban Affairs, 39(3), 323-334.

Buffel, T., \& Phillipson, C. (2016). Can global cities be 'age-friendly cities'? Urban development and ageing populations, Cities, 55, 94- 100 .

Buffel, T., Phillipson, C., \& Scharf T. (2012). Ageing in urban environments: Developing 'agefriendly' cities, Critical Social Policy, 32 (4), 597-617.

Fuchs, C. (20I5). Social media and the public sphere, TripleC: Open Access Journal for a Global Sustainable Information Society, I2 (I), 57-10I. 
Harvey, D. (2012). Rebel cities: From the right to the city to the urban revolution, Brooklyn, NY: Verso.

Kitchin, R. (1998). 'Out of place,' 'Knowing one's place': Space, power and the exclusion of disabled people, Disability and Society, 13 (3), 343-356.

Law, L. (2002). Defying disappearance: cosmopolitan public spaces in Hong Kong, Urban Studies, 39(9), 1626-1643.

Lefebvre, H. (1991). The production of space, trans. Donald Nicholson-Smith, Oxford: Blackwell.

Malone, K. (1999). Growing up in cities' as a model of participatory planning and 'place making' with young people, Youth Studies Australia, I8 (2), 17-23.

Malone, K. (200I). Children, youth and sustainable cities, Local Environment, 6(I), 5-I2.

Manfredini, M. (2017). The augmented meta-public space: Interpreting emerging transductive territories in enhanced centres of consumption," The Journal of Public Space, 2 (3), I I I- 128.

Manfredini, M., \& Jenner, R. (2015). The virtual public thing: De-re-territorialisations of public space through shopping in Auckland's urban space, Interstices: Journal of Architecture and Related Arts, 16, 70-81.

Manfredini, M., \& Ta, A.-D. (2016). Co-Creative urbanism: The production of plural evolutionary spatialities through conflicts and complicities between public and private in the streets of Hanoi, Vietnam, Joelho, Journal of Architectural Culture, 7, I32-I55.

Manfredini, M., \& Ta, A.D. (2017). The production of pluralistic spatialities: The persistence of counter-space territories in the streets of Hanoi, Vietnam, in R. Galdini, A. Marata \& M. Spada (Eds.), Creative cities: Public space and everyday places (pp. 373-38I), Rome: CNAPPC.

Manfredini, M., Xin, T., \& Jenner, R. (2017). Transductive urbanism: A method for the analysis of the relational infrastructure of malled metropolitan centres in Auckland, New Zealand, Athens Journal of Architecture, 3 (4), 4 I I-440.

Mitchell, W. J. (2003). Me++: The Cyborg Self and the Networked City. Cambridge, MA: MIT Press.

Morimoto, I. (20I5). Tourism, consumption and the transformation of Thamel, Kathmandu, in C. Bates \& M. Mio (Eds.), Cities in South Asia (pp. 309-325), New York, NY: Routledge.

Sennett, Richard (2018). "The open City," in UN-Habitat, R. Sennett, R. Burdett \& S. Sassen (Eds.), The Quito Papers and the New Urban Agenda (90-95), Abingdon, Oxon: Taylor and Francis.

UN-Habitat (2016). The New Urban Agenda, http://habitat3.org/wp-content/uploads/NUAEnglish.pdf.

Reeves, D. E., Parfitt, B., \& Archer, C. (20I2). Gender and urban planning: Issues and trends: Gender and Urban Planning (HS/050/I2E), Nairobi, Kenya: United Nations Human Settlements Programme.

Reeves, D. E. and Zombori, E. (2016). Engendering cities: International perspectives from Aotearoa New Zealand, Town Planning Review, 87 (5), 568-587.

Steinfeld, E., Maisel, J., \& Levine, D. (2012). Universal design: Creating inclusive environments, London: Wiley.

\section{To cite this article:}

Manfredini, M., Lo, A. and Reeves, D. E. (2018). Give Us Space! Augmented public space geographies in the changing public/private relationships. The Journal of Public Space, 3(I), 17I-I 78. DOI: 10.5204/jps.v3il.327

This article has been peer reviewed and accepted for publication in The Journal of Public Space. Please see the Editorial Policies under the 'About' section of the journal website for further information.

This work is licensed under a Creative Commons Attribution - Non Commercial 4.0 International License - https://creativecommons.org/licenses/by-nc/4.0/ 